\title{
PUGNAS POR EL CONTROL DE LA UNIVERSIDAD DESPUES DE LA EXPULSION DE LOS JESUITAS
}

\author{
Antonio MESTRE SANCHIS \\ Universidad de Valencia
}

La expulsión de los jesuitas produjo en la España de la segunda mitad del XVIII una convulsión enorme, tanto en el campo de las formas externas de religiosidad como en las manifestaciones culturales. No pretendo estudiar ahora los complejos problemas ocasionados en las personas e instituciones dirigidas y orientadas por los padres de la Compañía, o en la crisis de conciencia ante la represión de devociones (como la del Corazón de Jesús) antes fomentadas. Mi interés se centra en el análisis de los efectos del extrañamiento en los estudios universitarios y concretamente en Valencia '.

Desde luego, resulta evidente que el decreto de extrañamiento de los jesuitas produjo, de hecho, una efervescencia reformista en la Universidad. Es lógico. Porque, desde el momento en que empezó la campaña antijesuita, una de las razones alegadas fue la decadencia cultural que habían propiciado los padres de la Compañía a quienes se les atribuía el control de los instrumentos de poder. Así, los reformistas establecieron siempre una conexión entre la llegada al poder de los manteístas y la reforma de las letras. Los trabajos de Pérez Bayer, con el apoyo de los Secretarios del Despacho de Estado Ricardo Wall y Grimaldi, el nombramiento de Manuel de Roda para la Secretaría de Gracia y Justicia, y hasta la gracia de Alcalde de Casa y Corte y la pensión vitalicia concedidos a Mayáns, fueron presentados entre los grupos interesados como el medio de superar las deficiencias y el retraso cultural español.

Desde esa perspectiva se comprende la expectación suscitada por el decreto de expulsión de los jesuitas. Expectación más acusada, si cabe, en la Universidad, donde la alternativa establecida en las escuelas, con sus correspondientes cátedras, dejaba un vacío capaz de despertar grandes ambiciones en los hombres de letras con apetencias en la carrera docente. En consecuencia, es preciso distinguir, desde el primer momen-

1 Además de la bibliografía fundamental sobre las universidades del XVIII, en especial la de Valencia, la fuente básica del presente estudio es la documentación oficial del Consejo de Castilla. Complemento necesario ha sido el epistolario de Mayáns, al que hago frecuente referencia, y que se conserva en el Colegio de Corpus Christi (Patriarca) y en el fondo Serrano Morales del Ayuntamiento de Valencia. 
to, el interés sincero por la reforma de los planes de estudio y las deficiencias del sistema, del arribismo por acceder a los puestos de enseñanza vacantes por decreto gubernamental. Todo ello, sin olvidar las íntimas implicaciones entre la reforma y la ambición personal, tan frecuentes en la psicología humana.

Es necesario aludir a la existencia previa de escuelas claramente establecidas y delimitadas. Por un lado, los tomistas que, identificados con los partidarios de los dominicos, ejercían el control en la interpretación de la doctrina de santo Tomás en la teología y en los estudios filosóficos. El contrapunto estaba formado por la escuela antitomista, que poco a poco fue identificándose con la escuela jesuítica-suareciana, con las líneas diferenciadas en el campo de la metafísica, la ciencia media o el probabilismo en el campo de la teología y la moral. Este predominio de las dos grandes escuelas no suprimía la existencia de otras de menor entidad: escotista, cátedra de Durando... En esas circunstancias, resulta comprensible que los tomistas capitalizaran toda la animadversión clerical, universitaria y social, hacia los jesuitas, cuyo aumento se percibe a lo largo del siglo.

Las pasiones despertadas por las distintas escuelas son conocidas y los escándalos estudiantiles, suscitados al socaire de la fiesta de los patronos, eran frecuentes. Así, entre otras decisiones gubernamentales, el Consejo de Castilla ya advirtió a la Universidad de Valencia, en 24 de septiembre de 1757, del necesario control que debía ejercerse "sobre demostraciones públicas a nombre de escuela". Estas pasiones iban a desencadenarse en un solo sentido, después del decreto de expulsión.

Las escuelas, organizadas y cerradas en defensa de las ideas y del grupo, constituían una lacra de la Universidad española de la época. Así lo expresaron con claridad los tres primeros planes de estudios, redactados después de la expulsión de los jesuitas, que insisten en la supresión como único medio de reforma. Mayáns, desde Valencia, Olavide en Sevilla y Tavira catedrático de Salamanca, insisten en la necesidad de acabar con las escuelas, que ellos identifican con las órdenes religiosas. Era, por tanto, deficiencia a nivel nacional. Naturalmente, muchos años después de que las escuelas hayan dejado de ser controladas por las órdenes religiosas, continúan en nuestras universidades los clientelismos y las escuelas basadas en ideologías. Estamos, ciertamente, ante otro problema, pero que no deja de hacernos pensar en esa constante histórica.

\section{LA LEGISLACION DEL CONSEJO SOBRE CATEDRAS JESUITICAS}

El decreto de expulsión de los jesuitas fue acompañado, desde el primer momento, de las frecuentes acusaciones de desviacionismo doctrinal. En este sentido, el Dictamen del fiscal Campomanes marca un hito. Pero no se reduce a planteamientos político-sociales (populismo), sino que entraña problemas morales. La misma acusación de que los padres de la Compañía defendían el regicidio y tiranicidio introducía acusaciones de índole moral, que se añadieron a las grandes discusiones académicas sobre la validez ética del probabilismo. La lectura de las pastorales de muchos obispos (Rodríguez de Arellano, Fabián y Fuero, Felipe Bertrán...)contribuyeron en gran manera a desacreditar la doctrina y enseñanza de los jesuitas.

La intervención del Consejo no se hizo esperar. Apenas dos meses después de la expulsión de los jesuitas, una polémica académica suscitada en Valencia dio motivo a 
la decisión gubernamental. El dominico Fr. Luis Vicente Mas de Casavalls publicó Incommoda probabilismi, donde atacaba la doctrina del probabilismo, teoría moral atribuida a los jesuitas. Con motivo de la polémica suscitada, el Consejo de Castilla estudió su contenido, que encontró conforme a la doctrina de la sesión 15 del Concilio de Constanza (1415), en que se impugnaba el regicidio y tiranicidio. En consecuencia, con el fin de acabar con la raíz de tan perniciosa doctrina, el Consejo permitió la venta libre de Incommoda probabilismi, obligó a graduados y profesores universitarios al juramento de defender la doctrina de Constanza y prohibió la enseñanza, ni siquiera como probable, de la doctrina del regicidio y del tiranicidio contra las legítimas potestades (23 de mayo de 1767).

Era el primer paso. En septiembre, el Consejo volvía a dictar normas sobre el acceso del profesorado a tareas docentes: la Universidad, ante cualquier oposición a cátedra, informará al Consejo de la fecha, ejercicios de que constarán las pruebas, persona que ocupa la presidencia... (19 septiembre 1767). Nadie puede dudar de que se trata de unas normas destinadas a aumentar el control con el fin de evitar la filtración de personas de ideología "peligrosa".

Pero el decreto fundamental se produjo en 1768. El 1 de julio, el Fiscal del Consejo presentaba su informe que, publicado en el mismo Consejo el 8 , aparece firmado por Carlos III el 12 de agosto de 1768. El título es suficientemente expresivo: "Que se extingan las cátedras de la Escuela llamada jesuítica y no se use de los autores de ella para la enseñanza". El decreto especifica la prohibición como libros de texto de las obras de Pedro Calatayud, Herman Busembaun y la aprobación del cardenal Alvaro Cienfuegos al Aenigma theologicum así como "otros" autores, sin concretar, entre los partidarios de las doctrinas consideradas específicas de la Compañía. Consideremos el alcance del decreto en el mundo universitario: de un plumazo desaparecían la mitad de las cátedras en las facultades de teología y filosofía y sus profesores quedaban cesantes.

El vacío y desconcierto en el mundo universitario fueron enormes. Apenas conocido el decreto de expulsión de los jesuitas, Mayáns, que no les tenía simpatía, expresaba el enorme vacío que con su marcha dejaban: "Aquí la juventud está animosa para llenar el vacío que han dejado los de la Compañía que, aunque estaba vanamente ocupado, por fin era grande" (Mayáns a Roda, 5-V-1767). La misma realidad observaba José Finestres, aunque con intención muy distinta, pues, en carta a su amigo don Gregorio, insistía en la dificultad para llenar el gran vacío dejado por los expulsos, especialmente en el campo de la gramática y de las humanidades (25-IV-1767).

En la mente de ambos eruditos se pensaba en la ausencia de las personas. Pero en el decreto del 12 de agosto de 1768 , se trataba de la supresión de las cátedras y, en consecuencia, desdotación de enseñanzas (al menos en principio) así como del cese de gran parte del profesorado que llevaba muchos años de docencia. Quien conozca el mundo universitario no necesita de ulteriores explicaciones para comprender las consecuencias de semejante decreto.

Esta disposición legal, repetida el 4 de diciembre de 1771, entrañaba una evidente depuración del profesorado (los antitomistas), a quienes se les prohibía optar a nuevas cátedras, al tiempo que despertaba unas expectativas insospechadas para los miembros de la escuela tomista. Las pugnas por el acceso a las cátedras que, a partir de ese momento, salieran a oposición, tenían que ser, por necesidad, muy duras. 


\section{LAS CIRCUNSTANCIAS CONCRETAS VALENCIANAS}

Este era el marco general de toda España. En Valencia, las circunstancias concretas nos permiten observar el proceso con mayor claridad, sin variar, por supuesto, estas líneas básicas.

Apenas expulsados los jesuitas, fue nombrado director del colegio de San Pablo (colegio de nobles, antes dirigido por los padres de la Compañía) José Segarra, pariente de Pérez Bayer. Segarra es hombre que debemos tener en cuenta. Antijesuita convicto, con el apoyo del hebraísta y ya preceptor de los Infantes reales, consiguió el nombramiento de canónigo y años después el de rector de la Universidad. Parece que su gestión al frente del Colegio no fue muy afortunada. Tuvo conflictos que superó con el apoyo del grupo de Bayer, pero los estudios de gramática decayeron hasta el extremo de que los alumnos abandonaron las aulas para matricularse en la Escuela Pía. Porque -aparecen las primeras contradicciones-quienes antes habían censurado a los jesuitas su control sobre las escuelas de gramática, se oponían ahora a que fuesen incorporadas a la Universidad. Empieza a vislumbrarse uno de los grandes problemas: el texto de Gramática Latina.

Segarra estará siempre respaldado por Pérez Bayer que, con el afecto de Carlos III repetidamente manifestado y el apoyo de Grimaldi y Roda, gozaba de enorme poder en la Corte. Apenas decretada la expulsión de los jesuitas, el hebraísta, que pasaba en Tortosa una temporada de recuperación después de una grave enfermedad, fue llamado urgentemente por el gobierno y nombrado preceptor del Infante Gabriel. Era, por tanto, el sustituto de los jesuitas en la enseñanza de la familia real. Y su influjo en las decisiones gubernamentales relacionadas con el nombramiento de canónigos de la catedral valenciana (el rector de la Universidad tenía que ser, por constitución, canónigo de la metropolitana) fue decisivo en el desarrollo y solución dada a los problemas universitarios.

Por su parte, Mayáns había recibido el encargo, por parte de Roda, de redactar un plan de estudios que pudiera servir de orientación al gobierno en la proyectada reforma universitaria. Don Gregorio redactó la Idea del nuevo método que se puede practicar en la enseñanza de las Universidades de España (1-V-1767), que envió al Secretario de Gracia y Justicia. Por mucha confianza que tuviera Roda en la capacidad intelectual y en la honradez del erudito, la distancia de la Corte era un factor esencial en los casos de decisión política. El único recurso de Mayáns radicaba en la correspondencia que, evidentemente, carecía de la eficacia requerida para una actuación política continuada. Sus frecuentes cartas a Campomanes, Fiscal del Consejo de Castilla en los asuntos universitarios, o al conde de Aranda mientras fue Presidente, no equilibraban la fuerza que, con su presencia, poseía Pérez Bayer. Además, no podemos olvidar la actitud centralizadora del gobierno. Por eso, aunque en la correspondencia del momento aparezcan los rumores de que Mayáns o el obispo auxiliar (Lasala, amigo de Bayer y después obispo de Solsona) serían nombrados director de estudios de la Universidad, no pasaron de cábalas. La dirección fue encargada a un Consejero de Castilla, con el consiguiente influjo del Fiscal Campomanes.

Son consideraciones a tener en cuenta para comprender muchos de los acontecimientos que veremos en las pugnas universitarias valencianas. Pérez Bayer, pese a sus veleidades filojesuíticas durante la década de los años 40 (oposiciones a la cátedra de 
hebreo de Salamanca y colaboración con Burriel en la comisión de archivos, bajo el patrocinio de Rávago) había sido tomista, íntimo de José Climent, el obispo “jansenista" de Barcelona, y de Felipe Bertrán, obispo de Salamanca e Inquisidor General, y se fue acercando cada vez más a los manteístas. Si a esto añadimos que el arzobispo de Valencia -y por tanto, canciller de la Universidad - será Fabián y Fuero, antes canónigo de Toledo y compañero de Bayer, y tomista radical, podemos adquirir una idea aproximada de la fuerza del partido tomista en la Universidad de Valencia.

Las cartas de Mayáns, que había pasado a residir en Valencia, nos permiten vislumbrar el proceso de fortalecimiento del partido tomista. En un principio, según vimos en la carta a Roda, se limitaba a señalar el vacío dejado por los jesuitas. O, como decía a Nava Carnero: "Ya se desterraron los bárbaros, falta desterrar de España la barbarie. Dios quiera que seamos instrumentos de esta gloriosa empresa" (23-VII1768). Pero, por lo visto, había muchos que se consideraban predestinados por la Divina Providencia para eliminar la barbarie cultural e introducir las nuevas luces procedentes del gobierno de Carlos III.

\section{LA APLICACION DE LOS DECRETOS Y LAS PUGNAS UNIVERSITARIAS}

El erudito pudo observar muy pronto que la expulsión de los padres de la Compañía no pacificaba las pugnas universitarias. En aplicación del decreto de 12 de agosto de 1768, se reunió el Claustro Mayor de la Universidad de Valencia. En plena coherencia con los aires que soplaban desde la Corte, acordó la supresión de las 3 cátedras de filosofía antitomista y las 6 cátedras de teología antitomista, 3 de las cuales tenían pavordía anexa. La protesta no se hizo esperar. Entre otras razones, porque las pavordías tenían una dotación especial y se regían por la Bula de Sixto V (1585).

Dadas esas circunstancias, el Consejo encargó al ministro de la Real Audiencia, Teodomiro Caro Briones, un informe sobre la situación universitaria valenciana (23XII-1768). Caro debería enviar un ejemplar de las Constituciones, el documento (bula pontificia) de creación de las pavordías, testimonio de la asignación en su momento de las cátedras a cada escuela así como de la adscripción de los actuales pavordes, texto o apuntes que explicaban los catedráticos antitomistas. Como era lógico, este memorial iba acompañado del informe del Claustro Mayor, de la ciudad y de los particulares interesados, documentos todos que se dirigieron al Consejo, que no dejaba de precisar sus ideas: deseaba tener datos para el caso de que no decidiera la extinción de las cátedras antitomistas y buscaba todas las precauciones posibles para extinguir el espíritu de la escuela jesuítica. Dos apuntes más sobre el oficio del Consejo de Castilla. Mientras el Consejo decidía lo más conveniente, puesto que había una cátedra de filosofía tomista vacante, provéase cuanto antes entre los profesores de dicha escuela y, sobre todo, prohibía escribir y publicar libros y folletos sobre este tema tan vidrioso.

En efecto, la documentación recogida fue muy varia: informe del Claustro Mayor, recurso de los antitomistas, representaciones de regidores y otras personas interesadas. Hasta el extremo de que, como decía el mismo Consejo: " Ha resultado formalizarse un voluminoso expediente, reducido a dos puntos". Adquiere especial importancia el carácter de los dos puntos en que centra su interés el Consejo.

"El uno, si han de quedar, o no, extinguidas en esa Universidad las cátedras de la 
citada escuela antitomista y prohibida la enseñanza a los pavordes y catedráticos de la misma escuela".

El segundo, "sobre arreglar la admisión de los opositores antitomistas a las cátedras que quedaron existentes y las precauciones que se deberá usar en el caso de ser admitidos para evitar las funestas consecuencias de una parcialidad dominante y de todo fanatismo".

Era necesario conocer la situación general española y el marco legal concreto respecto a la Universidad de Valencia para comprender la actitud de Mayáns. Porque el erudito debió considerarse una de las personas individuales interesadas en la reforma de los estudios. Y sobre el asunto escribió una larga carta al conde de Aranda, Presidente del Consejo de Castilla, fechada el 14 de febrero de 1769.

Venía a ser una reflexión sobre su plan de estudios, enviado dos años antes al gobierno, pero, al mismo tiempo, una respuesta a la solicitud del Consejo. Así, pues, insistía en la necesidad de dos cátedras de Sagrada Escritura, una de Nuevo y otra de Antiguo Testamento, cátedra de dogma, de moral y una de escolástica. Mayáns no era partidario de la supresión de la enseñanza de la escolástica, pero exigía que no hubiera disputas de escuelas: "Que haya una cátedra de teología meramente escolástica; esto es, en que, supuestas las verdades reveladas, y los dogmas de la religión y los consejos evangélicos, distinguidos de los mandamientos de la ley de Dios..., únicamente se trate de sentencias escolásticas provechosas para la declaración de las verdades reveladas, de las Tradiciones Apostólicas y de los dogmas católicos, y bastará una cátedra para todas las sectas escolásticas; mandando que ni se expliquen, ni se defiendan opiniones que sean más curiosas que útiles".

El temor a la aparición de facciones que se identificaran con una de las escuelas resulta evidente. Y Mayáns especificará que nunca debían permitirse cátedras de Santo Tomás, de Escoto, de Durando... (las de los jesuitas estaban ya suprimidas) porque, a su juicio, mantenían las facciones universitarias y, como no eran necesarias, el contenido positivo se explicaba en la cátedra de Escritura y dogma, las diversas opiniones, como históricas, corresponderían a la única cátedra de escolástica. Mayáns piensa que la teología más adecuada es la basada en la Biblia, Concilios y Santos Padres, pero no deja de expresar con claridad: "Por último, mientras habrá nombre de tomistas, habrá antitomistas. Mientras habrá escotistas, antiescotistas y así de los demás partidos'.

Pues bien, pese a sus temores, expresados con tanta viveza, el erudito verá el desarrollo de una escuela, que adquiere fuerza y empuje irresistible. En carta posterior al mismo Aranda, expresa con enorme plasticidad la situación valenciana: "En la teología todo es gritar viva santo Tomás, y cada uno enseña tan caprichosamente como quiere, sin explicar las Sacras Escrituras, sin enseñar los dogmas, ni los preceptos de la religión cristiana" (28-IX-1769). La preocupación del erudito parece aumentar de día en día; y en todas las ocasiones que se le presentan insiste en la idea de separar la Escritura, el dogma y la moral de las diversas opiniones de escuela. En esta línea, censura con especial dureza a la escuela tomista, porque es la más poderosa y la que sirve para escalar cargos. Valgan estas palabras de una carta a Juan Bautista Hermán, escogidas porque demuestran el sentido peyorativo que podía alcanzar el calificativo de tomista y el uso que se hacía en la vida académica, además de las implicaciones políticas subyacentes. 
"Dígame Vm., ¿qué quiere decir tomista en el sentido común? Yo entiendo que es un hombre que no lee a Santo Tomás y que quiere que creamos que le lee. En este sentido, ¿qué quiere decir antitomista? Es un hombre que quiere dar a entender que es contrario del otro y que tampoco lee al santo, sino que discurre como le parece..."

"¿Pues de qué sirve el nombre de tomistas sino de alborotar? Mientras habrá quien se llame tomista, habrá quien, si no se llama, se tendrá por antitomista, y lo será, y con razón..." .

"Aquí convendría (a) cuatro o cinco se privasen por un quinquenio de voto en la ciudad, para que no pusiesen en la Universidad maestros de su facción; aunque pueda dudarse cuáles son peores".

Me parecen textos luminosos. Los problemas de escuelas, o de grupos unidos en torno a una teoría teológica, no son grupos estrictamente intelectuales. Tienen una repercusión académica-universitaria innegable pero, además, una trascendencia político-social insospechada. Como hoy, claro. Porque, en el fondo, los "cuatro o cinco" a que alude Mayáns son regidores de la ciudad que colocan en las cátedras a "maestros de su facción',

Todas estas ideas aparecen expuestas con frecuencia en la correspondencia del erudito y, por supuesto, en las cartas dirigidas al Fiscal Campomanes, a quien había enviado el plan de estudios redactado en 1767 y, además, recordaba en 30 de junio de 1770 que el director de la Universidad debía evitar las facciones. Era su gran preocupación que iría aumentando, según se acercaban las oposiciones a las pavordías.

El asunto era vidrioso después de la supresión de las cátedras antitomistas. Si bien el real decreto de 12 de agosto de 1768 había descalificado textos y maestros de la escuela jesuítica, las dudas surgían al analizar la relación antitomista-jesuita. Desde una perspectiva sociológica, parece muy coherente la aparición de una poderosa corriente que identificara a todos los antitomistas con los partidarios de las ideas jesuíticas prohibidas por real decreto. Era una simplificación: todos aquellos que no habian formado parte de la escuela tomista quedaban rechazados para cualquier cargo docente. En el fondo, la raíz política: al aceptar sólo a los partidarios de la doctrina de Santo Tomás, el gobierno fomentaría las ambiciones de una escuela, de una facción.

Ante esta corriente, que iba adquiriendo fuerza, Mayáns escribe una larga carta al Conde de Aranda de 14 de febrero de 1769, ya aludida. En ella el erudito hace una síntesis de sus planteamientos generales en el campo de la reforma de los estudios. Y al hablar de la actitud a tomar respecto al acceso a la docencia universitaria, aparecen con claridad las preocupaciones sobre el problema de los antitomistas.

En primer lugar, la supresión de textos y la eliminación de profesores y políticos (regidores que controlaban la Universidad de Valencia) que se habían manifestado partidarios de los jesuitas.

"Además de esto, las elecciones de maestros deben ser de personas indiferentes y que solamente enseñen la doctrina católica. Esto se conseguirá en Valencia, privando de voto para diez años a los regidores que más se han señalado en mantener la facción social (jesuitas); de manera que ni asistan al ayuntamiento cuando se trate de la provisión de las cátedras, ni voten en las elecciones de maestros"'. Y, junto a los regidores que disponen de las cátedras en las oposiciones, los profesores que enseña- 
ron las doctrinas de los expulsos también deben quedar excluidos: "Los catedráticos, que han dictado ser lícito el regicidio, exclúyanse de la enseñanza pública y no se admitan a ella, ahora sean antitomistas o tomistas... Los que han sido sostenedores de los expulsos después de su expulsión, ni continúen en enseñar públicamente, ni en adelante sean admitidos a los concursos a cátedras".

Ahora bien, después de estos juicios tajantes, la postura de Mayáns se flexibiliza y adquiere matices. Respecto a los que han defendido el probabilismo, "tomado en el sentido de autorizar las opiniones laxas", deben abjurar de esos "errores", tanto tomistas como antitomistas. Eso sí, serán apercibidos de que, en caso de reincidir en la enseñanza de tales doctrinas, "serán privados de las cátedras".

Más todavía, en la facultad de filosofía hay profesores que han ocupado cátedras antitomistas de las que han sido privados. Como no tenían culpa personal alguna, porque las cátedras así estaban tituladas, podrán presentarse a las oposiciones a nuevas plazas que, por supuesto, no llevarán la etiqueta de tomista, escotista... El mismo criterio adoptará respecto a las cátedras de teología antitomista. Cuando no haya culpa personal, podrán presentarse a cualquier cátedra, sea de Escritura, dogma, moral o escolástica. Pero, en cualquier caso, estarán obligados a renunciar previamente a defender la teoría del probabilismo laxo.

Aunque estos criterios, expuestos en carta al Conde de Aranda, eran generales y tenían alcance nacional, el erudito podía observar con sus propios ojos la realidad universitaria valenciana. Los intereses de grupo y de partido prevalecían sobre el valor de los candidatos. Y conste, que Mayáns no condenaba sólo al partido más fuerte, que era, en esos momentos, el tomista. Valga el comentario sobre la actitud de dos canónigos que intrigaban a la muerte de un pavorde: "Estos partidos débiles tiran a unirse contra el tomístico para prevalecer. Lo cierto es que unos y otros son bárbaros y faccionarios".

En contraste, su actitud resulta clara y transparente respecto a que, dado que ya no existen escuelas, debe elegirse al mejor. "Ayer vino a tentarme el Dr. Beneito. Yo le respondí que, si la elección de pavorde estuviera en mi mano, ni elegiría a hombre que hiciese profesión de tomista, ni de antitomista, sino (hablando de teología) a un hombre de bien $\mathrm{y}$, por consiguiente, buen vasallo del rey y que fuese sabiamente cristiano, esto es, inteligente en las Divinas Escrituras, sólidamente dogmático y buen teólogo moral. Lo demás es dejarse llevar del espíritu de partido' (4-XII-1770). Estas palabras iban dirigidas al Fiscal del crimen de la Audiencia Valenciana, Juan de Casamayor, del grupo de Roda, a quien, indica explícitamente Mayáns, debe comunicar estas cosas.

\section{EL PODER DE LOS TOMISTAS Y EL DECRETO DEL CONSEJO}

Una última consideración sobre la génesis de las facciones universitarias después de la expulsión de los jesuitas. Dado el poder de Pérez Bayer y el favor con que protegía a sus amigos (conocido de todos era el caso del canónigo Segarra) se ve rodeado de muchos que desean medrar, han formado una facción, "enemiga de los hombres de mérito, entendiendo yo por tales a los de buenas costumbres, a los fieles vasallos del rey, a los enemigos de la doctrina corrompida y a los que saben bien lo que 
pretenden enseñar'" (26-XI-1771). Estas duras palabras fueron escritas al Fiscal del Consejo de Castilla.

Después de cuanto llevamos dicho, se deduce que en Valencia, tras unos años de depuración, había un grupo dominante, llamado tomista, que deseaba controlar la enseñanza universitaria. Pero, aparte de los partidarios fieles a la Compañía, existían profesores, no suarecianos, y que habían sufrido marginación por parte de los jesuitas, pero tampoco eran tomistas. Estos últimos intentaron incluir a los independientes en el grupo de los suarecianos-antitomistas. Bastaba identificar a los antitomistas con los jesuitas. Era una forma de descalificarlos e impedir su competencia en unas posibles oposiciones.

A la vista de tantas polémicas, el Consejo dio su dictamen el 27 de enero de 1772. En un intento de suavizar las tensiones, las decisiones eran mucho más matizadas que en el decreto del 12 de agosto de 1768 y, en el fondo, se acercaba mucho (como podrá observar el lector) al criterio expuesto por Mayáns en sus cartas a Aranda y a Campomanes. Así, pese al acuerdo del Claustro Mayor de la Universidad de Valencia en que solicitaba la supresión de todas las cátedras de teología y filosofía antitomista (2-IX1768), decretaba el restablecimiento de la "enseñanza en todas, con calidad de que absolutamente se extinga de palabra y por escrito en las conclusiones, grados, materias, acuerdos u otros actos, el nombre de antitomista, llamándose en adelante todas las cátedras, sus profesores y oyentes, de filosofía y teología sin otra adición, denominación o título".

Era el punto básico y fundamental. Porque, dentro de la mayor coherencia, las disposiciones irían matizando el pensamiento del Consejo en esta línea.

Los catedráticos y pavordes antitomistas, cuyas cátedras fueron extinguidas por el Claustro Mayor de 2 de septiembre de 1768, serán restablecidos en el ejercicio de la enseñanza, previo juramento ante el Vice-canciller de la Universidad de que ni por escrito, privada o públicamente, “defenderán, enseñarán, ni seguirán las opiniones de los regulares expulsos en las cuestiones que llamaban de escuela y eran distintivo de la jesuítica"'.

El interés por parte del Consejo de extinguir cualquier recuerdo de escuelas resulta evidente, pues insiste en que los profesores deben "explicar en todas las cátedras de artes y teología sin diferencia de escuela ni partido, entendiéndose esto interinamente, y sin perjuicio del nuevo método que en lo sucesivo se establezca...' .

De acuerdo con estos criterios, el Consejo decreta que se saquen a oposición las cátedras que deben restablecerse (las antiguas de los antitomistas) así como las que quedaren vacantes, "y se admitan a ella indis(tin)tamente todos los que se presentaren, hayan seguido o no por lo pasado la escuela jesuita'. Eso sí, siempre debía preceder el juramento de no defender las doctrinas propias de la Compañía (regicidio y probabilismo). Y lo más importante para nosotros: "Que se saquen a concurso las pavordías primarias y demás que se hallen de Patronato y que la Junta de Patronato admita a oposición indistintamente a todos los profesores que se presentaren, forme ternas para cada una de por sí y, sin perjuicio de su patronato, las remita por esta vez al Consejo, con una lista de todos los opositores que hubiere habido a cada cátedra, con las relaciones de sus méritos y ejercicios".

Bien mirado, era el intento legal de enmendar, o paliar, las graves consecuencias que el decreto de supresión de cátedras antitomistas podía provocar, y en parte había 
ya provocado, en las universidades. El Consejo debió temer, además, que, eliminados los jesuitas, surgiera otro grupo que, bajo la capa de "tomistas", monopolizara la enseñanza y constituyera una "facción" excesivamente poderosa. De ahí que, eliminado el peligro que, a juicio del gobierno, constituían las doctrinas jesuíticas, diera libertad de opción a todos.

Al mismo tiempo, la velada alusión del Consejo al "nuevo método que en lo sucesivo se establezca" tenía gran alcance. El mismo Consejo indicaba al Claustro Mayor que encargase a personas competentes la redacción de un "método de estudios..., con discernimiento de las diversas facultades". Dicho en otras palabras, solicita un plan de estudios para la Universidad de Valencia. Es el momento en que se encarga a Mayáns la redacción de los planes de estudio para las facultades de derecho civil y canónico (1772). Y, mucho más importante, la reacción de los antitomistas que, animados por la actitud del Consejo, llegaron a redactar un ambicioso plan de estudios, también en 1772, estudiado por Salvador Albiñana en su tesis doctoral. Dejemos este tema, que nos llevaría muy lejos, y volvamos a la libertad de concurrir a las oposiciones concedida a los antitomistas.

\section{LA INTERVENCION DEL ARZOBISPO FABIAN Y FUERO}

Como siempre ocurre, desde la publicación del decreto gubernamental a su cumplimiento, transcurre un largo período; especialmente cuando de oposiciones universitarias se trata: reconocimiento de cátedras vacantes, publicación de convocatorias, aceptación de candidatos, nombramiento del tribunal... Es decir, las votaciones de los regidores, finalizados los ejercicios de los 16 candidatos, se celebraron el 1 de marzo de 1774. En ese entretiempo, se habían producido cambios importantes en la cúpula de la autoridad universitaria.

Tras la muerte del arzobispo Tomás Azpuru, embajador español en Roma, que ni siquiera había visitado su diócesis, accedía a la sede valenciana Francisco Fabián y Fuero. Antiguo canónigo de Toledo (con Lorenzana, Rodríguez de Arellano y Pérez Bayer) y tomista convicto, había ocupado la diócesis de La Puebla de los Angeles (México) donde había publicado una pastoral contra los jesuitas con motivo de la expulsión. Es conveniente señalar el pensamiento tomista del nuevo arzobispo, porque constituirá uno de los puntos esenciales en el desarrollo de los acontecimientos.

La correspondencia de Mayáns nos permitirá acercarnos a la figura del nuevo prelado desde varias -y no siempre idénticas - vertientes. Fabián y Fuero hacía la entrada oficial en Valencia en noviembre de 1773. Pero desde agosto de dicho año aparece la figura del arzobispo en las cartas del erudito. Ya el 3 de agosto conocía Mayáns que, en su pastoral de despedida de La Puebla de los Angeles, Fabián y Fuero aconsejó su Filosofía Moral como texto para los seminaristas. Esta será una noticia "de que me alegro tanto más cuanto mayor es el desprecio de nuestros patricios", que repetirá con frecuencia a sus corresponsales. En ese sentido, procurará que a la llegada a la península, o a su paso por Toledo, le transmitan sus saludos.

Pero no deja de constituir un síntoma preocupante la insistencia con que repite el deseo de que la presencia del nuevo arzobispo acabe con las banderías y facciones que dividen la Universidad. Entre las múltiples alusiones, escojo estas expresivas palabras: 
"Bien puede estar cierto de que tendrá feliz pontificado; porque los sectarios de la gente social ya estarán desengañados de sus falsas esperanzas. La consideración de que tendremos un prelado que premiará a todo pretendiente benemérito, hará abominar el espíritu de facciones... Hay odios capitales por las cabezas de las facciones. Pero dejará de haber cabezas cuando venga la que sólo debe serlo" (Mayáns a Aurelio Ballester, 28-VIII-1773).

Queda clara la preocupación del erudito: una vez superada la prepotencia de los jesuitas, la justicia de Fabián y Fuero, que premiará a los beneméritos, acabará con las banderías. Desde esa perspectiva es menester observar la actitud de Mayáns ante el nuevo arzobispo. Porque se da un evidente contraste entre una primera fase, en que predominan los elogios, y otra en que las críticas resultan duras.

En la primera fase, los elogios del erudito a Fabián y Fuero se centran en sus virtudes y en su actitud ante el fanatismo. Respecto a las virtudes personales, sus palabras son claras: "El Sr. arzobispo de Valencia llegó el jueves por la mañana al convento de Nuestra Señora del Socorro, extramuros de esta ciudad, y por la tarde fui a besarle la mano y quiso que lo abrazase. Es un prelado santo, docto, humanísimo y caritativo" (20-XI-1773). Estos elogios, expuestos en carta al Consejero de Castilla Fernando Velasco, se repetirán en cartas a su hermano Juan Antonio, confidente de sus juicios: "El Sr. arzobispo se hace de amar y de temer" (30-XI-1773). "Este Sr. arzobispo se porta muy bien, con caridad y afabilidad; y se hace mucho de temer" (4XII-1773), y comenta algún sermón que gustó a los oyentes.

Fabián y Fuero observó, desde el primer momento, los problemas que creaba al erudito la ausencia de su hermano Juan Antonio, residente en la canonjía de Tortosa. Y quiso ayudar a los hermanos Mayáns, ofreciéndose a escribir al Confesor del rey: "El Sr. arzobispo me envió ayer un recado por su secretario, diciendo si quería ir; al instante fui y me enseñó una copia de lo que había escrito al P. Confesor; que era una llana en cuarto y se reducía a decir que eras de edad provecta, de buen ejemplo y docto, de manera que te necesita aquí, y así que haga que consigas del rey el canonicato vacante. Nadie lo sabe, sino el amigo; ni aun que he sido llamado. Fui introducido por una puertecita excusada" (30-XI-1773). (Juan Antonio fue nombrado canónigo de Valencia en abril de 1774, gracias al favor de Manuel de Roda, que se apresuró a comunicarlo al erudito).

Pero muy pronto las noticias que transmite el erudito demuestran los problemas de fondo. La raíz hay que buscarla en la actitud del arzobispo, que apoyó, de manera decidida y no siempre justa, a los tomistas. Todavía no había transcurrido un mes de su llegada a Valencia cuando surgían las primeras fricciones con los agustinos, porque el Provisor de la diócesis, con el apoyo del arzobispo, censuró las conclusiones enviadas al Capítulo Provincial (14-XII y 18-XII-1773). El disgusto parece haber sido más generalizado entre los regulares. Así, mientras el arzobispo permanecía aislado en la casa de descanso de Puzol, "tiene contra sí a casi todos, tanto tomistas como suaristas, frailes, clérigos, faltos de subsidio, privados de mandar, desposeídos de empleos, emposesados sin inteligencia..." (11-I-1774).

Naturalmente, en la conversación mantenida con el arzobispo, Mayáns le habló de los problemas suscitados por el decreto del Consejo imponiendo su Gramática Latina como texto en las universidades de la corona de Aragón, y por tanto en la de Valencia, y aprovechó la ocasión para prevenirle de "que estaba circuido de hombres falsos. Me 
respondió que lo conocía y que no hacía sino mirar a todos lados sobre hombros...". Esta oposición subterránea afloró a las primeras divergencias. El arzobispo empezó a manifestar sus preferencias por la escuela tomista, lo que provocó la reacción de quienes se consideraban postergados. El texto de Mayáns es muy expresivo de la oposición y de las razones que la provocaron:

"El Sr. arzobispo va recogiendo licencias de confesar y predicar; sobre lo cual hay grande alboroto; especialmente por parte de las monjas, que no quieren admitir a los confesores nuevos, todos los cuales son tomistas". Y añadía que, respecto a las próximas oposiciones a pavorde, Fabián y Fuero se inclinaba por Miralles y Esteve, eliminando a todos los demás (28-II-1774).

\section{LAS OPOSICIONES A PAVORDE Y EL INFORME MAYANSIANO}

En esas circunstancias tuvo lugar la oposición a la pavordía vacante en la Universidad de Valencia. Dada la libertad concedida a opositar, tanto a tomistas como a antitomistas, fueron 16 los candidatos, 7 de ellos tomistas y 9 antitomistas. Por supuesto, los candidatos del arzobispo, Manuel Miralles y Diodoro Esteve, eran tomistas. Pero los votos de los regidores no se adaptaron al deseo de Fabián y Fuero. Y según las directrices dadas por el Consejo, votaron la terna para enviar a Madrid. En la votación para el primer lugar, se dio el siguiente resultado: Vicente Peris, antitomista, obtuvo 14 votos; Manuel Miralles, tomista, 6; y Carlos Beneito, tomista, 2.

El resultado fue, por tanto, inapelable. Pero esto no cambió la proporción de fuerzas, favorable a los tomistas. Dentro de la confusión creada en la Universidad por las múltiples denominaciones, la prepotencia de los tomistas era evidente: "Los quondam suaristas defenderán conclusiones siguiendo a san Agustín. Los filósofos tomistas noveles están con ánimo de defender los sistemas noveles contra santo Tomás. Veo y callo. Los tomistas están tan insolentes, que ayer públicamente dispararon más de una docena de cohetes" (8-III-1774). (Aunque sea interrumpiendo la narración de los hechos, no puedo menos de aludir al matiz expuesto por Mayáns del cambio de postura de las escuelas y, sobre todo, al hecho de que la escuela tomista fuera el vehículo de penetración de la filosofía moderna, que en otros textos el erudito calificará de materialista).

Y como no podía menos de ocurrir, dada la dinámica de los hechos, los tumultos llegaron a la Universidad: la caballería rodeó el edificio y la infantería entró en el patio; se publicó bando contra los estudiantes imponiendo pena de azotes, y con destierro o presidio, a los que se encontrasen con armas o piedras; la ciudad se alborotó y acudió el gentío para impedir el castigo de los azotes. La raíz del tumulto: "Esto nace de la limosna hecha sólo a los tomistas". Quien daba la limosna era el arzobispo.

A esto debemos unir la desazón creada entre los regulares por las preferencias de Fabián y Fuero. Así, los suaristas estaban molestos porque las limosnas no les alcanzaban a ellos. Los franciscanos, agustinos, mercedarios y carmelitas también manifestaban su disgusto porque el arzobispo, después de 4 meses, no les había devuelto la visita. El erudito señalaba un caso concreto: al Dr. Escrivá no se le dio ayuda (manteo y libros) porque no se le reputó tomista (15-III-1774). Y la actitud del arzobispo parecía inalterable: "El Sr. arzobispo está hecho un fiero contra los suaristas. Me dijo 
que el rey le había dicho que había muchos Judas. Lo he callado, por ser la voz tan señalada" (9-IV-1774).

¿Puede extrañar que, en esas circunstancias, los tomistas opositores a la pavordía, que habían visto frustradas sus esperanzas, presentaran recurso al Consejo? No es necesario discurrir mucho para adivinar que su acusación consistía en una simplificación: los antitomistas defendían las doctrinas prohibidas de los expulsos y el Dr. Peris, como antitomista, debía ser desposeído de la pavordía. Y el Consejo envió el recurso a Mayáns para que emitiera su juicio. El informe, que ahora publico, es la respuesta del erudito.

El informe tenía que ser, después de cuanto llevamos dicho, conforme al resultado de la oposición, aunque hubiera recaído en antitomista que, según las noticias de don Gregorio, había sido marginado por los jesuitas. Un detenido análisis del contenido del informe desbordaría las posibilidades del presente trabajo. Sólo me detendré en apuntar algunos aspectos que completen la exposición anterior.

En primer lugar, el informe mayansiano constituye un documento sociológico de primer orden. Es la expresión de las actitudes de diversos grupos sociales ante la perspectiva de plazas que inesperadamente les permite un ascenso socioeconómico notable. Y sobre todo, facilita la comprensión de la multiplicidad de sentidos que adquieren las palabras (tomista y antitomista, en este caso) cuando de pugnas ideológicas se trata.

Don Gregorio desarrolla, a lo largo del informe, sus ideas básicas sobre la reforma de los estudios: cátedras de Escritura, dogma, moral y escolástica (como historia de las teorías). Reincidía en el criterio desarrollado en el plan de estudios y en las cartas al Conde de Aranda y a Campomanes, a que hemos aludido.

Repulsa de las escuelas y de todo encasillamiento ideológico que pudiera contribuir a crear un partido o facción. Se trata de una actitud básica y esencial, pues el clientelismo ha constituido - y constituye, hoy mismo- uno de los defectos históricos de la Universidad española. Su actitud, que hemos analizado con detenimiento, parece haber influido en el decreto del Consejo de Castilla, especialmente en lo relativo a la licencia de presentarse a las oposiciones a los antitomistas que hubieran jurado no defender las doctrinas de la llamada escuela jesuítica.

La exigencia de premiar al más capaz, acompañada de la libertad personal, aunque dentro de las condiciones del juego que, para el erudito, eran la doctrina cristiana, la "sana doctrina en lo tocante a las acciones humanas", y el respeto a los decretos reales que constituían el marco legal.

Aparte de estas consideraciones, las oposiciones a pavordía analizadas en este artículo constituyeron un hecho clave para entender muchos de los acontecimientos culturales de fines del XVIII en Valencia. Porque las consecuencias de estas divergencias, resultado de la oposición y el informe de Mayáns, fueron graves y de indudable alcance.

Produjo, por supuesto, la tirantez -si no ruptura, porque muchos años después hubo una relación cultural para editar Opera omnia de Vives- de los hermanos Mayáns con el arzobispo. Esta tirantez tendrá múltiples manifestaciones. Fabián y Fuero propiciará las intrigas del grupo de Pérez Bayer que, para complacer al duque de Béjar, protector de Juan de Iriarte, apoyaba la imposición de la Gramática latina del humanista canario. Con ello impedía la adopción de la Gramática mayansiana que, pese al 
mandato expreso del Consejo, repetido por 3 veces, no fue aceptada por la Universidad de Valencia. En esa línea, no dudará en rechazar el Organum rhetoricum et oratorium, adaptación mayansiana del tratado de Nebrija (1773).

La agresividad del partido tomista, unida a la protección y el favor del arzobispo, provocó un instinto de defensa entre otros grupos menores. No todos pensaban de idéntica manera. Había escolásticos discrepantes del tomismo, agustinianos, ilustrados independientes... Y en un momento concreto, vieron en el nombre de un Mayáns, con una trayectoria antijesuítica bien conocida, la posibilidad de unificación y autodefensa. Así se explica la candidatura de Juan Antonio Mayáns, sin estudios universitarios, pero canónigo de la metropolitana, para el rectorado de la Universidad. Ni que decir tiene que los tomistas - y el mismo Fabián y Fuero- se opusieron con encono a la elección. Y aun después de ganada la votación, la impugnaron con tenacidad.

En íntima relación con este planteamiento está el hecho de que, durante el rectorado de Juan Antonio Mayáns, se inicia un significativo acercamiento al obispo de Murcia Rubín de Celis, para conocer y, en parte, aceptar los planes de estudio establecidos en el Seminario de San Fulgencio. Y más importante todavía, la correspondencia establecida entre los hermanos Mayáns y el general de los agustinos Francisco X. Vázquez con la finalidad de potenciar el estudio de la doctrina de San Agustín en la Universidad. Era una hábil maniobra: dado que el Consejo de Castilla hablaba indistintamente de la enseñanza de las doctrinas de santo Tomás y de san Agustín, utilizaban el estudio del obispo de Hipona para defenderse de la prepotencia de los tomistas. Así se comprende la importancia que adquirió el agustinismo en Valencia.

A partir de ese momento, las cartas de Mayáns respiran un aire de dureza contra Fabián y Fuero anteriormente desconocido: atacará sus injusticias, aireará ante las autoridades (Fiscal y Consejeros de Castilla) los atropellos cometidos (procesos del Dr. Llansola, del Dr. Peris -ambos antitomistas y opositores a la aludida pavordía- y especialmente al canónigo Juan Bautista Hermán, íntimo de los Mayáns), censurará su ambición y las intromisiones en la vida universitaria... Sólo durante los últimos años de vida del erudito se calmarán las tensiones. El arzobispo se preocupará de la salud de doña Margarita, la esposa de Mayáns, que sufrió una hemiplejía, encargará le regalen y obsequien durante los últimos días pasados en Chulilla. Y, en el campo cultural, la Opera omnia de Vives, trabajo de gran envergadura, acabará uniendo en un proyecto común los ideales ilustrados de ambos. 


\section{M.P.S.}

Tratándose ahora de la provisión de una cátedra de teología expositiva con pavordía anexa presentemente vacante en la Universidad de Valencia, y habiendo presentado al rey nuestro señor los catedráticos y profesores de la escuela tomista de dicha Universidad un Memorial, que su magestad ha remitido a $S$.A., se ha dignado $S$.A. de mandarme que en vista de él exponga yo lo que tenga por conveniente. Veo que V.A. me ha metido en un laberinto tan intrincado, que no podré salir de él felizmente, si no sigo el hilo de las reales pragmáticas y sabios acuerdos de V.A. sobre lo que se debe ejecutar en este asunto.

Para lograr pues el devido acierto, anticiparé ciertos presupuestos innegables i distinguiré i declararé los vocablos de ambigua significación; porque de otra manera ya se toman en un sentido ya en otro; y de su confusión nacen las sofisterías que llegan a perturbar el sosiego público; porque transcienden a las cosas propias de la religión cristiana y del estado político, tratándose los unos a los otros (hablo por lo general) sin caridad, ni apariencia de ella. Los presupuestos que anticipo son tres: es a saber.

Nadie debe ser admitido a los concursos de petición de cualquier cátedra destinada a la enseñanza pública, si no es hombre de costumbres cristianas y de aquella doctrina que el apóstol san Pablo llamó sana, i que sepa explicarla y haya dado muestras de constante aplicación.

Cualquiera que siga alguna de las que caracterizaban la secta de la gente social, esto es, la doctrina herética del regicidio i la que, por cierto sistema depravado y al mismo tiempo complaciente, relajaba las costumbres cristianas, no puede ser admitido a los concursos de peticiones de cátedras, haya seguido, o no seguido, antecedentemente la escuela jesuítica, o antitomista o cualquiera otra.

Las elecciones deben hacerse prefiriendo los habilitados más beneméritos a los que no lo son tanto.

Anticipados estos presupuestos, antes de empezar el examen del Memorial de los tomistas, habemos de saber en qué sentido se quiere que entendamos esta voz general de tomista, distinguiendo sus varias significaciones, a cada una de las cuales se opone el vocablo antitomista.

O la palabra tomista significa al que sigue a santo Tomás de Aquino en todo lo que nos ha dejado escrito, o en la mayor parte.

Cualquiera que le siga en todo, consiguientemente le seguirá admitiendo como verdaderas las falsas decretales, inventadas contra la verdadera disciplina eclesiástica antigua i contra los incontrastables derechos públicos de las supremas potestades seglares. Le seguirá, teniendo por verdaderos los libros De divinis nominibus, atribuidos a san Dionisio Areopagita, fingidos en el quinto siglo cristiano con notable daño de las explicaciones verdaderas de las cosas divinas $\mathrm{i}$ comentados como genuinos por santo Tomás. Le seguirá con una demasiada adicción a la doctrina de Aristóteles, reprobada por impía en gran parte y prohibida en tiempo de santo Tomás, y nuevamente detestada por los hombres más sabios de la cristiandad como corrompedora de la fílosofía moral. Finalmente, le seguirá en algunos deslices de la pluma del santo, confesados como tales por los más insignes seguidores de su doctrina.

El que sea antitomista en éstas y semejantes aserciones no errará, antes bien debe serlo.

Si por tomista se entiende el que sigue a santo Tomás en la mayor parte de lo que enseña, o se trata de dogmas de la religión católica que profesamos y debemos profesar, o de otros asuntos por sí indiferentes.

Si se trata de los dogmas con los cuales se conforma santo Tomás, debemos pensar que 
fue un teólogo dogmático eminentísimo, y cualquiera que contradiga a los dogmas católicos, y consiguientemente a santo Tomás que los cree, enseña y explica sabiamente, el tal deberá ser reputado, no solamente por antitomista, sino también por hereje.

Pero si se trata de asuntos por sí no dogmáticos, sino indiferentes, o éstos tienen conexión con los dogmas católicos, o no la tienen. Si la tienen, los teoremas que en dichos asuntos se resuelvan, deben ser conformes a los dogmas; y en este sentido así circunstanciado cualquier antitomista deberá ser reprobado por oponerse a dicha conexión.

Si las proposiciones resueltas no la tienen con el dogma católico, deberá prevalecer la razón a la mera autoridad humana de cualquiera que sea. Y si la razón no es clara, quedará al cuidado de los que aman y buscan la verdad atender a la preferencia del autor más ingenioso, más docto y más erudito, más aplicado a la averiguación de aquel asunto. $\mathrm{Y}$ así en este particular el buscador y averiguador de la verdad, unas veces será tomista y otras antitomista; y otras, ni uno ni otro, porque santo Tomás dejó de tratar innumerables asuntos.

De los que se titulan suaristas dejo de hablar, así porque en la Universidad de Valencia no había cátedra de Francisco Suárez, como en la de Salamanca, instituida en el tiempo en que yo cursaba en ella, como porque este nombre de suarista no se oyó en la Universidad de Valencia hasta que se acabó en ella la casta de los eruditos discípulos del maestro Pedro Juan Núñez i tal cual por vana adulación a los expulsos regulares quiso llamarse suarista, desde cuyo tiempo los tomistas por oprobio empezaron a llamar suaristas a los antitomistas, siendo así que entre éstos había acérrimos contradictores de Suárez y de la escuela llamada jesuítica, con profanación del adorable nombre de Jesús.

Distinguidos de esta manera los tomistas y antitomistas, veamos ahora qué aplicación debe hacerse de estos nombres.

Hay muchos que se atribuyen este glorioso nombre sin haber distinguido ni estudiado las verdaderas obras de santo Tomás. Otros, que se tienen por tomistas, únicamente por haber elegido maestros que se nombran así. Pero yo quisiera saber si merecerán el nombre de tomistas, que se arrogan, los que, llamándose tales, se oponen a la doctrina, no solamente del santo, sino también a la de la Iglesia Católica, instruyendo a sus discípulos en la pestilencial herejía del materialismo y defendiéndola públicamente en sus conclusiones impresas; contra cuya herejía oró en el primer sermón que predicó en esta ciudad el reverendo arzobispo de Valencia.

Al contrario el nombre de antitomista se da a muchos que no le merecen, como los que no estudiaron en tal escuela, los que meramente aprendieron la Gramática en las aulas de los regulares expulsos, o que únicamente estudiaron la lógica o la metafísica en sus escuelas, sin haber aprendido alguna de las doctrinas suyas características o distintivas de ellos por las cuales deban ser reprobados.

Estos tales en la profesión de la doctrina ni son rigurosamente tomistas, ni antitomistas. Pueden Ilamarse apasionados a unos i a otros; y su pasión, según los particulares objetos que tenga, puede ser criminosa o loable, cuando se trata de castigarla o de premiarla.

Después de esta anticipación de proposiciones, que me parecen ciertas, propondré sencillamente el examen que V.A. me ha mandado que haga yo del Memorial que han presentado al rey nuestro señor los catedráticos y profesores de la escuela tomista de esta Universidad.

Dicen (iré proponiendo a la letra lo que se lee en dicho Memorial para que juzgue V.A. lo que me parece de todo su contenido). Dicen pues que en los tiempos en que los regulares de la extinguida compañía estaban en los reinos de V. M. fueron tantas las injusticias, que los suplicantes padecieron en las elecciones para las principales cátedras, llamadas pavordías, que 
el Sr. Dn. Fernando Sexto, en el año 1757, expidió un real decreto mandando que de las cinco pavordías de la Facultad teológica, dos se proveyesen en la de la escuela tomista, y otras dos en la de la escuela suarista, o antitomista; y la otra turnara entre ambas escuelas. Todo se ejecutó conforme al real decreto. Hasta aquí el Memorial.

Por mucho que se quejen los catedráticos de la escuela tomista de lo que les dieron que sentir los regulares de la compañía, no se quejarán bastantemente. Pero al mismo tiempo padecían iguales o mayores persecuciones muchos que, habiendo estudiado en la escuala antitomista, no querían seguir las depravadas máximas de los expulsos. Pero omitiendo esto, que no es propio de nuestro asunto, pues no se trata de desagraviar a los injuriados de los expulsos, sino de que consiga la pavordía vacante el que sea más benemérito, guardando en todo la justicia distributiva; será del caso repetir ahora lo que mandó entonces el señor rey don Fernando Sexto, porque algunas circunstancias de aquel decreto están estudiosamente omitidas en este Memorial.

En el día, pues, cinco de febrero del año 1757, mandó el señor rey don Fernando Sexto, a consulta de V.A., en 22 de noviembre del año antecedente 1756, que luego que V.A. recibiese su real carta, formase nuevo estatuto, reglando la provisión de las cinco cátedras de teología, que tenían anexa pavordía, entre las dos escuelas, suarista y tomista, esto es, dos a cada una y la quinta alternativamente, pero sin que las dos de Escritura se juntasen en una escuela; y distribuyendo las siete cátedras restantes en la misma forma que las antecedentes, a cuyas siete cátedras fuese libre oponerse los profesores, así seglares como regulares de aquella opinión, a que respectivamente correspondiere. Se vio, obedeció y cumplió esta real cédula en el claustro mayor celebrado en 17 de febrero de 1757 .

En aquel tiempo había dos escuelas principales, a saber, las llamadas tomista y antitomista, por apodo suarista, voces que de ninguna manera son sinónimas, porque la suarista está justamente reprobada y desterrada de todas las Universidades sujetas al rey de España, y no debe quedar residuo de ella, respecto de ser la misma que de otra manera, aunque muy impropiamente se Ilama jesuítica; siendo así que en algunas cuestiones capitales es contraria a la sacrosanta doctrina de Jesucristo. La escuela antitomista ya hemos visto que, según lo que significa el nombre de antitomista, se puede tomar en diferentes sentidos. Por esto la escuela antitomista, hablando absolutamente, ya no debe ser nombrada, ni reputada como existente, por ser éste un nombre de división, contradicción y facción opuesta; y por estar justamente mandado que, en adelante, no haya sino una escuela, a la cual sean admitidos indistintamente los que fueron de la escuela antitomista, con ciertas precauciones establecidas en la real cédula de 27 de enero del año 1772.

Supuesta pues la división y existencia de las dos escuelas, tomista y antitomista, en tiempo del señor rey don Fernando VI, con el fin de contener los ánimos de la una y de la otra, y tolerándose entonces la permanencia de dichas dos escuelas, según el estado de las cosas de aquel tiempo, mandó el señor rey don Fernando Sexto que se turnara. Esta era la infeliz continuación de entonces. Unas veces tenían mano más poderosa en los negocios los de una escuela; otras, los de otra; y se tomaba por medio de pacificación el turno o alternativa en las elecciones, el cual turno o alternativa únicamente puede tener lugar cuando hay distintas y contrarias partes, habilitadas para retener o conseguir ciertos derechos, como suelen tenerle las ramas de una familia o descendencia y algunas confraternidades, o comunidades, que se quieren conservar. Pero cuando se manda que no se conserven, ni se instituyan de nuevo sectas diversas o partidos de contrarias opiniones, sino que todos conspiren en seguir una principal y necesaria doctrina, como es la cristiana, sin formar cuerpos diversos que mantengan sus emulaciones, sin 
más razón que haber elegido voluntariamente alistarse en uno o en otro partido; las alternativas turnales son contrarias a la justicia distributiva; porque, debiendo elegirse para enseñar las ciencias los más hábiles y beneméritos; la Divina Providencia no ha ordenado que una vez el más benemérito sea de un bando i otras de otro, sino que, habiendo la misma Divina Providencia distribuido graciosamente los talentos con una maravillosa desigualdad conveniente al bien de cada uno, a la sociedad humana i a la gloria del mismo Dios, sucede que las potencias del alma mayores, o menores, y la aplicación a los estudios, mayor o menor, son las causas de la diversidad de los méritos a que deben atender las supremas potestades i todo hombre racional y justo.

Por estas razones el señor don Felipe Quinto de gloriosa memoria, estando en San Lorenzo, día 20 de octubre del año 1721, firmó un decreto, que es el auto 29 , tit. 7 , lib. 1 de la Nueva Recopilación, en que dijo: Son repetidos los decretos en que tengo ordenado que, para la provisión de las cátedras no se atienda al turno, sino al mérito de los opositores.

Sería yo muy impertinente si repitiese a V.A. el grande número de pragmáticas y cédulas reales que prohíben las alternativas, o turnos, en las elecciones de las cátedras, como perturbativas del mayor mérito y del sosiego público. V.A. que lo ha mandado lo sabe mejor que todos. A V.A. pues toca juzgar si los catedráticos y profesores, que suponen existente la división de las escuelas tomista y antitomista, pretenden bien que se mantenga esta división de escuelas por medio de la alternativa, muchas veces prohibida, y que debiera prohibirse con mucho rigor contra cualquiera que en adelante se atreva a pedir que se observe en las elecciones de maestros de las Universidades literarias; y juzgará también V.A. si los autores del Memorial tienen, o no tienen, razón legal para pretender que se excluyan del obtento de las cátedras los que su magestad ha querido habilitar para los concursos y oposiciones literarias, en caso de que su mérito, considerado comparativamente, sea superior.

Añaden los autores del Memorial que, como los catedráticos tomistas, que entonces (esto es, en tiempo del señor rey don Fernando) fueron provistos en las pavordías, eran hombres de edad y cansados por sus tareas literarias, fallecieron todos poco después, de suerte que en las pavordías de teología no queda ninguno de la escuela tomista, y solamente las disfrutan tres pavordes que hay suaristas; por consiguiente, en virtud del real decreto, debieran ser nombrados para las dos vacantes que hay al presente, dos profesores de la escuela tomista. Debe suponerse que la causa de que había pocos tomistas para conseguir las pavordías era porque ocupaban las cátedras de su partido muchos religiosos de la orden de santo Domingo y de san Agustín; y viendo muchos manteístas tomistas que no eran atendidos, despechados, seguían el camino de los curatos, que les facilitaban los mismos religiosos. Los suplicantes callan las cátedras que obtienen, y solamente hablan de las que tienen anexa pavordía porque valen más.

Parece que los suplicantes se explican de manera que intentan imponer a V.A. la obligación de haber de nombrar pavordes a dos tomistas, no haciendo mención de que el que ha de ser elegido ha de tener la prerrogativa del mérito, del cual nunca hablan.

Prosiguen diciendo al rey nuestro señor de esta manera: " El Consejo de Castilla habiendo abolido la división de las escuelas por provisión comunicada al claustro mayor de esta Universidad, en 27 de enero de 1772, de que acompaño copia, habilitó a a los profesores antitomistas, haciendo antes juramento de no seguir las doctrinas jesuíticas, para todas las cátedras y señaladamente para las dos pavordías vacantes; al parecer por no haberse entonces hecho presente a este supremo tribunal el derecho privativo que tenían a ellas los profesores tomistas, en virtud de la citada real cédula, que no está revocada".

No me atrevo a interpretar el artificio de estas cláusulas por no hacer odiosos a sus autores. 
Solamente diré que en ellas se acusa el olvido de V.A. en no haber tenido presente un derecho, habiendo sido condicional para los casos de las vacantes en tiempo en que existían y se permitían las dos escuelas; y dicen que la cédula real no está revocada, habiéndose revocado manifiestamente con la prohibición de la división de las sectas contrarias y con el expreso mandamiento de que sean preferidos los más beneméritos.

Se meten más adentro los suplicantes diciendo que, por esta habilitación y permiso del Consejo, dominando en los patronos de la Universidad el partido jesuítico, según lo han acreditado aún en estos años en la provisión de varias cátedras, se hallan los suplicantes en la triste situación de ver inútiles sus estudios en las doctrinas de san Agustín y santo Tomás, que V.M. manda se enseñen, estando muy expuestos a perder las cátedras, que por decretos reales, y por constituciones de la Universidad, les corresponden, y la enseñanza pública a ser depositada en sujetos que no pueden estar instruidos en las referidas doctrinas, por no haberse criado en ellas y haber seguido siempre las contrarias. En este contexto del Memorial hay mucho que atender y considerar. Tácitamente se reprende en él la habilitación y permiso de V.A. admitiendo indistintamente a los que pueden ser útiles en las escuelas.

Expresamente se notan los patronos de la Universidad como hombres del partido jesuítico. A qué especiales asuntos de doctrina o a qué hechos de los dichos patronos hace relación este jesuitismo que se les imputa, yo no lo sé, porque para saberlo sería menester entender individualmente cuáles de las doctrinas llamadas jesuíticas siguen los que componen el cuerpo místico de la ciudad; y contrayendo esta criminal acusación al asunto presente, sería menester hacer una inquisición comparativa de los méritos de los provistos en las cátedras, cotejándolos con sus competidores no provistos, examinando bien las conclusiones de unos y de otros, que pudieron ser ajenas de algunos de los que las firmaron, pero por fin las adoptaron; examinando asimismo los ejercicios literarios públicos, en que por parte de los que examinan debe haber mucha inteligencia y ninguna pasión. Cuando en España se trataba el importantísimo negocio de haber de imprimir religiosamente la Sagrada Escritura, según la verdad del texto hebraico, el cardenal Cisneros, que era uno de los mayores ministros cristiano-políticos que ha tenido la monarquía de España, no duđó valerse de algunos que habían sido rabinos, como lo vemos en la historia de la Biblia Complutense, y solamente los supersticiosos tuvieron que murmurar, y sus murmuraciones no hicieron efecto alguno en los ánimos de los hombres sabios. Lo que habemos menester es que no se enseñe, ni se practique, la perversa doctrina, justísimamente prohibida. En los demás, las acusaciones no sean generales, sino de hechos singulares dignos de enmienda, y tal vez de severo castigo.

Es cosa de hecho, que ninguno de los que votan las cátedras ha estudiado teología en alguna Universidad; y que de los que han estudiado la filosofía, o parte de ella, hay diez vocales tomistas, once antitomistas, y ocho que no han estudiado ni filosofía ni teología. Si las elecciones de los que últimamente han sido nombrados catedráticos han sido buenas o malas, en lo tocante a la buena o mala doctrina, se ha de examinar por lo que han defendido, dictado y explicado los que han sido elegidos. Si algunos de los elegidos, de cualquier partido que sean, han escrito o enseñado de palabra alguna de las doctrinas reprobadas de la escuela llamada jesuítica, deben ser castigados según su mérito, pero si han defendido, escrito y enseñado lo que deben, y como deben, injustamente son acusados de sus émulos con delaciones generales que nada prueban; porque la verdad de una proposición general únicamente puede fundarse en las verdades de las proposiciones singulares incluidas en ella. Yo no he leído lo que han dictado los catedráticos últimamente elegidos, pero habiéndome traído conclusiones muchos de los dos partidos, sin cstudio alguno, y solamente por la lectura casual de tal cual artículo, he observado 
que muchos de los que se llaman tomistas han introducido en esta Universidad (no digo con mala intención, sino por haber copiado indiscretamente los escritos de algunos impíos) la grande herejía del materialismo, contra la cual predicó el reverendo arzobispo de Valencia en su primer sermón que hizo en la escuela pía. I si los de la escuela llamada antitomista han dictado alguna doctrina contraria a la religión católica, ninguna razón han tenido sus émulos en haberla disimulado y más habiendo precedido la delación del materialismo hecha, según dicen, por alguno de los llamados antitomistas.

En lo que toca a la doctrina de santo Tomás en que los autores del Memorial se suponen a sí mismos bien instruidos, afirmando también que no lo están sus contrarios, yo he observado que, antes que V.A. propusiese como maestros principales de las explicaciones de los dogmas de la religión cristiana a estos dos varones insignes de doctrina y santidad, había muy pocos de uno y otro bando, tomista y antitomista, que leyesen sus obras. Ahora veo con mucho gusto mío que no vienen de fuera de España índices de libros venales que no abunden de las utilísimas obras de santo Tomás, y justamente con ellas vienen también algunos, aunque pocos ejemplares de las del gran padre de la Iglesia san Agustín. Yo considero que me dirán que las unas sirven más a la teología escolástica que las otras. Pero yo tengo una duda, y es ésta. En caso de que la doctrina de santo Tomás sea contraria a la de san Agustín, ¿ a quién de los dos se debe seguir? El maestro frai Melchor Cano, perpetua lumbrera de la orden de santo Domingo, en el libro 10 de sus Lugares teológicos, cap. 5, celebra mucho a santo Tomás pero añade que nadie debe anteponerse a san Agustín. Esto es hablar en general, pero yo más particularmente siento que en cualquier asunto de dogma católico debemos seguir absolutamente a las Sagradas Escrituras y a las Tradiciones divinas, según la Iglesia católica las entiende y enseña; y en consecuencia de esto, nos conformamos casi siempre con la interpretación de uno y de otro santo, los dos instruidos en la doctrina de la Iglesia católica.

En el conocimiento de la lógica puramente tal, los dos fueron eminentes; y ésta es una arte racional en que no disintieron sino rarísima vez.

En la metafísica intencional sucede lo mismo. En la real anduvieron a la par, habiendo precedido el uno al otro. Lo mismo sucedió en la física, habiéndose hecho después en ella notables progresos, por causa de la invención de varios instrumentos y de nuevas experiencias.

En el modo de filosofar san Agustín fue platónico; santo Tomás aristotélico. Platón pareció más acomodable al cristianismo, y por eso fue seguido de los Santos Padres de los siglos primeros. Además de que por sus estudios eran más inclinados a la secta platónica que a lá secta epicúrea y aristotélica. Aristóteles en gran parte fue cristianizado por santo Tomás, pero no del todo; de lo cual modernamente se ha escrito con harta diligencia. Si amamos la verdad, el modo de filosofar de Platón es distinto del de Aristóteles, y consiguientemente son irreconciliables muchas veces uno y otro santo.

Fuera pues de los dogmas de la religión católica, para cuya interpretación propuso V.A. como guías principales a san Agustín y santo Tomás, en los otros asuntos de que no habló V.A., ¿a cuál de los dos debemos preferir?

Los tomistas pretenden que a santo Tomás, príncipe de la teología escolástica. Los otros que a san Agustín, sumamente ejercitado en todo género de ciencias.

Si se permite que haya dos escuelas, una tomista y otra agustiniana, la guerra escolástica será mucho más cruel que hasta ahora, porque cada uno de estos dos partidos se abroquelará con la autoridad del santo de su mayor devoción. Considero pues que, así como V.A. ha mandado que nadie se llame antitomista, mande también que nadie se apellide tomista, ni agustiniano; porque si uno, en los asuntos dogmáticos sigue a santo Tomás o a san Agustín, o a uno y otro 
santo, debe llamarse cristiana. Si a sabiendas y con pertinacia, se aparta de los dogmas, es y debe llamarse hereje.

Si en otros asuntos sigue la verdad, no debe ser reprendido, aunque deje de seguir a cualquier escrito que no sea canónico. Inculcar continuamente el nombre de santo Tomás, por parecer y ser tenido por tomista en todo lo que se dice i para insultar a otros, cuando se trata del mérito comparativo, y no de solos nombres muchas veces mal aplicados, es conmover los ánimos y querer hacer odiosos y aborrecibles a muchos, ciertamente beneméritos y sin duda inmunes de aquellas bien fundadas sospechas que deben ser exclusivas de los premios a que aspiran los indignos, $o$ por falta de doctrina, o por sobra de malicia y de infidelidad.

Vemos que la afectada inculcación del nombre de tomista se practica en muchísimas conclusiones impresas, en los argumentos públicos y en sus respuestas, y lo que es más, en los sermones, hasta llegar a exhortar a las sagradas vírgenes y a las mujeres seglares a que sigan a santo Tomás, cuya santidad y sabiduría venero cuanto cualquier otro, pero no le citaré sino para fortalecer una opinión que por sí no sea evidentemente cierta y requiera la exterior autoridad de algún varón de eminente doctrina en aquel asunto de que se trata. Fuera de que no siempre que se cita a santo Tomás, se cita con verdad; antes bien muchas veces con tal estupidez que las citas, por ser falsas, son calumniosas al gloriosísimo santo; de lo cual pudiera yo alegar algunos ejemplos muy recientes de los mismos que están gritando desaforadamente.

Tachar a bulto a los que antes se llamaban antitomistas, porque no están informados en la doctrina de santo Tomás y de san Agustín, es nota general que se verificará en unos y se falsificará en otros. No es verdadera consecuencia decir: no se sigue a santo Tomás, luego no se entiende; porque puede entenderse y no seguirse.

Otro mayor inconveniente se ofrece en seguir en todo, o casi todo, la doctrina de santo Tomás; porque se le han atribuido muchas obras que totalmente no son suyas; otras suyas se han interpolado. Entrarán las dudas en qué partes de ellas se han interpolado. Se observarán errores en las que indiscretamente se han atribuido al santo. Muchos querrán ser conciliadores de unas y de otras. Quiero decir de las verdaderas y de las fingidas. Este será seminario de perpetuas disputas y discordias que fácilmente puede hacer V.A. que no sucedan con sólo mandar que sea lícito, y aun loable, seguir a santo Tomás con discreción y prudencia, sin apellidarse tomista, para insultar con este nombre a los que tienen por émulos en las competencias de las cátedras o pavordías.

Volviendo al Memorial, lo único que los pretendientes deben alegar a V.A. son sus méritos, y lo único que deberá excluir a sus antagonistas es, si actualmente son fieles a Dios y al rey o no; o, si dan sospechas bien fundadas de no serlo. Pero en lo demás sea la doctrina totalmente cristiana, quiero decir, uniforme en los dogmas, sana en lo tocante a las acciones humanas, libre con prudente elección, erudita sin afectación en la ilustración de las verdades, nada rencillosa y totalmente ajena de contiendas caprichosas.

Yo pienso que sobre todo lo dicho, de ninguna manera daré mejor mi parecer que, copiando a la letra el que dio públicamente fray Alonso de Castro, de la orden de los menores de la regular observancia, uno de los grandes teólogos que ha tenido España, en su insigne obra contra las herejías, libro I, capítulo 7, en donde admirablemente describió el infelicísimo estado de su tiempo en orden a las disensiones escolásticas nacidas de los partidos tomista, escotista y ocamista, y le describió con tantas y tales circunstancias que son las mismas que hoy concurren.

Empieza Castro citando aquel terrible dicho del Espíritu Santo, que en el salmo 115, dice: Omnis homo mendax, y después le amplifica desta manera: “Agustín, en la epístola a Gerónimo, que en el orden de las otras epístolas es la diez y nueve, dice: Yo por cierto confieso a tu 
caridad que a solos aquellos libros de la Escritura, que ya se llaman canónicos, he aprendido deferir esta reverencia y honor de creer firmísimamente, que ningún autor de éstos está, escribiendo; o si acaso encontrare algo en sus escritos que parezca contrario a la verdad, no dudo que es otra cosa sino estar viciado el código, o que el intérprete no lo alcanzó, o que yo de ninguna manera lo he entendido. Pero leo a los otros de tal modo, que por más que sobresalgan en cuanta santidad y doctrina quiera, no por eso pienso que es verdad, porque ellos lo han sentido así, sino porque podrán persuadirme que no se apartan de la verdad, o por otros escritores canónicos, es a saber, de la Sagrada Escritura, o por alguna razón probable, esto es, evidente. Ni pienso yo, hermano mío, que tus libros se lean así como si fueran de profetas y de apóstoles, de cuyos escritos, que carecen de error, es cosa irreligiosa dudar. Esté esto lejos de tu piadosa humildad y de tu veraz modo de pensar de ti mismo.

Después de haber anticipado esto, fray Alonso de Castro añadió lo que se sigue: "Confieso que no puedo refrenar mi saña cuantas veces veo a algunos tan adictos a los escritos de ciertos hombres que tienen por impío al que en algo, aunque sea erudito, se aparta de su sentir; porque quieren que los escritos de los hombres se reciban como oráculos de dioses, y les prestan aquel honor que solamente se debe a las Sagradas Letras. Porque no habemos jurado seguir las palabras de algún hombre, sino las palabras de Dios. Yo, por cierto, diría que es una servidumbre muy miserable estar de tal manera adicto al parecer humano, que de ninguna manera sea lícito repugnarle; cuya servidumbre padecen éstos que totalmente se sujetan a los dichos do santo Tomás, o de Escoto, o de Ocam, y para conseguir los nombres de aquéllos, a quienes parece que juraron seguir, los unos se llaman tomistas, los otros escotistas, los otros ocamistas. Pablo, por cierto, mandó cautivar nuestro entendimiento en obsequio de Cristo, pero no en obsequio de un hombre. Con lo cual sucede que estos que tan ligeramente pronuncian sobre la herejía, no pesando de qué cosa hablan, muchas veces se hieren con su propia saeta y caen en el hoyo que preparaban contra otros, porque querer contar las escrituras humanas en el orden de las divinas, a esto con más verdad Ilamaría yo herejía. Lo cual hacen estos que piensan que es cosa impía disentir de los escritos humanos, como si fueran divinos. Cuyo género de hombres he visto yo que han llegado a tanta locura, que no han recelado echar esto al público en un sermón: "Cualquiera que se aparte de la sentencia de santo Tomás se ha de juzgar por sospechoso de herejía." ¡Oh fuertes predicadores de la palabra de Dios! O más verdaderamente diría yo, de la palabra de santo Tomás. Deberá pensarse, pues, que san Buenaventura es sospechoso de herejía, porque en muchas cosas se aparta de santo Tomás. ¿Se dirá, pues, que san Anselmo es sospechoso de herejía, porque contra el sentir de santo Tomás dice que no es amado de la Virgen el que rehúsa celebrar la fiesta de la Concepción? Con todo esto no quisiera yo haber dicho estas cosas de manera que alguno piense que yo con estas palabras quiero morder los hombres de algún instituto u orden, porque entre ellos conozco muchos hombres doctos y cuerdos y verdaderamente piadosos, a quienes estas cosas desagradan muchísimo, cuando se trata de ellas, o las dicen otros las más veces indoctos; porque también me desagrada muy mucho el que parezca que nuestra fraternidad haya jurado en las palabras de Escoto. Yo, por cierto, venero la santidad del bienaventurado Tomás. A su doctrina defiero mucho, porque ha ilustrado mucho la Iglesia, pero no por eso pienso que se le ha de favorecer tanto que convenga que en todo se sienta con él. Ni yo jamás creería esto de la humildad de santo Tomás que quisiera que uno esté tan adicto a sus dichos, que no estuviese siempre aparejado a sujetarse al que enseñe cosas mejores, porque muchas veces él mismo retractó su sentir". Hasta aquí el doctísimo fray Alonso de Castro, a cuyo sabio discurso no tengo que añadir siquiera una palabra. 
V.A. juzgue si aquel insigne varón habló al caso. Los dominicanos, que dice que eran de su mismo sentir en orden a la sentencia de santo Tomás, fueron los maestros Francisco Vitoria, establecedor del moderno método escolástico en la Universidad de Salamanca, y su discípulo Mclchor Cano, cuyo juicio sobre este asunto es dignísimo de leerse en su libro 12 De locis theologicis, cap. 1, en donde el maestro Cano llegó a escribir que, según su juicio, el maestro Vitoria conseguía mayor alabanza disintiendo de santo Tomás que sintiendo con él. Tanta era su reverencia, cuando disentía.

Descubiertos los flacos fundamentos del Memorial que vamos examinando, sin pasar por alto cosa alguna, prosigue de esta manera: "Con lo cual se frustran las rectas intenciones de V.M. y se fomenta el espíritu jesuítico que V.M. desea exterminar de sus dominios".

Con esto quieren decir que, excluyendo a los que su magestad admite a las oposiciones de las pavordías vacantes, y eligiendo a algunos de los que han firmado el Memorial, aunque en los actos literarios no hayan dado públicas pruebas de su excelencia y superioridad en comparación de sus competidores, se hará justicia, y no se frustrarán las rectas intenciones de su magestad, ni se fomentará el espíritu jesuítico.

No es esto lo que V.A. ha mandado practicar en todas las Universidades de los dominios de S.M. Contra cualquiera que se trate de excluir, se ha de probar que merece ser excluido por causa de seguir alguna sentencia distintivamente característica de los llamados jesuitas. De otra manera los autores del Memorial de suplicantes pasarán a querer ser asesores del legislador sin otro motivo que el de su propio interés, y por eso, movidos de él, concluyen así: "Los suplicantes recurren a la alta justificación de V.M., suplicando humildemente se digne mandar que las dos pavordías vacantes se confieran a dos de los profesores que han seguido la escuela tomista, conforme al decreto del señor don Fernando Sexto, reservándose V.M. para el mayor acierto la elección por esta vez, y sin perjuicio de las últimas providencias, y de que puedan obtener cátedras los que siguieron la escuela suarística, o antitomista, después de algunos años, cuando podrán juzgarse instruidos en las doctrinas de san Agustín y de santo Tomás'. Esta es la petición de los autores del Memorial, pretendientes de una justicia versátil en favor suyo.

Ya habemos visto que el decreto del señor rey don Fernando fue en suposición de mantenerse las dos escuelas. Ahora V.A. ha mandado que solamente haya una. Los suplicantes colocan el mayor acierto de su magestasd en que ellos sean preferidos por esta vez. Así lo solicita su propio interés, pero no lo pide su mérito.

Dicen que esto que piden no se opone a las últimas providencias de V.A. de que puedan obtener cátedras los que siguieron la escuela suarística, o antitomista, después de algunos años, cuando podrán juzgarse suficientemente instruidos en las doctrinas de san Agustín y de santo Tomás. Este modo de hablar supone que los autores del Memorial están bien instruidos en la doctrina de los dos santos; y si fuera así, siendo superiores a sus émulos, no tendrían más que desear. Pero importa a su causa que por ahora sus contrarios se tengan por inhábiles en la doctrina de uno y de otro santo, y que para en adelante se les dé tiempo para instruirse en clla. ¿Qué número de años es el que piden para esta instrucción? ¿Por qué ahora no se ha de juzgar comparativamente si los que equivocadamente se llaman suaristas y antitomistas (voces muy distintas por sus significados) están ya debidamente instruidos, o no, en la doctrina que deben enseñar? Este no debe ser un examen de todo el partido, que contiene doctos e indoctos, jesuitas y antijesuitas, sino meramente de los concurrentes en las oposiciones. Yo he conocido, y conozco, antitomistas muy tomistas, muy enemigos de los regulares expulsos, capitalmente perseguidos de ellos; y no alcanzo qué razón puede haber para excluir un hombre de esa calidad y de méritos sobresalientes. 
Antes de manifestar yo mi modo de pensar, conviene que V.A. esté informado de algunos hechos, de los cuales se han originado estas grandes disensiones y discordias, y del estado presente de las cosas, y después verá V.A. el fácil remedio que pueden tener los males actuales.

Cristiana y católicamente mandó el rey nuestro señor que se extinguiese la escuela llamada jesuítica, en todo lo tocante a las proposiciones heréticas y sediciosas, como la de ser lícito el regicidio y otras relajadas; y V.A. sabiamente ordenó todo lo perteneciente a una tan loable ejecución. Los hombres sabios tuvieron aquellas reales órdenes por necesarias; los estudiosos, unos se desengañaron, otros no querían admitir el desengaño, porque no oían la verdad, ni querían oirla por sus preocupaciones. El vulgo ignorante discurría según las que tenía buenas, o malas, según sus directores. En lo que toca a los que en esta Universidad seguían la carrera de los estudios, casi todos pensaron que lo que había mandado el rey nuestro señor, con acuerdo de V.A., era conforme a los mandamientos de nuestra sagrada religión, y consiguientemente a la razón natural y política cristiana. Con todo eso, según se decía, no faltaban (como en todo lo restante de España y en las Indias) quienes no podían creer que la doctrina prohibida enseñarse, hubiese sido adoptada y practicada de unos hombres que ellos respetaban como verdaderos sabios. Los hombres de escuela consideraban que les tenía cuenta para sus medras seguir to que se les mandaba, y más teniéndolo por bueno. Aunque esto no impedía que otros con disimulo ocultasen la pasión que tenían a los que pensaban ser inocentes y creían que volverían. Los tomistas empezaron a querer excluir a sus antiguos émulos, se inflamaban los ánimos y era tiempo de sospechas. Pareció conveniente al claustro mayor de esta Universidad suspender el egercicio de las cátedras a los antitomistas hasta que V.A. hubiese examinado si convenía, o no, que continuasen en la enseñanza pública. Se vio que la intención de V.A., en vista de aquella suspensión, fue querer que los catedráticos de la Universidad de Valencia, y todos los demás que hubiere en los dominios del rey nuestro señor, sean buenos cristianos y católicos, hombres peritísimos en las artes y las ciencias y que sepan enseñarlas con buen método y claridad, y se apliquen a ello. En consecuencia de esto, V.A. se sirvió de mandar (entre otras providencias dirigidas al establecimiento de las cátedras de esta Universidad y de su ejercicio) que la Junta de Patronato de esta Universidad admitiese a oposición indistintamente a todos los profesores que se presentasen, formando ternas por cada uno de por sí, y que, sin perjuicio de su patronato, las remitiese por esta vez al Consejo con una lista de todos los opositores que hubiese habido a cada cátedra, con la relación de sus méritos y egercicios.

Así lo ha ejecutado la ciudad patrona, y lo que V.M. me manda es que exponga e informe yo de qué escuela es cada uno de los opositores, y lo demás que se me ofrezca y parezca.

En cuanto a los opositores, el número de ellos y los distintivos de su antecedente profesión, son éstos, según el orden de su antigüedad:

1. El doctor D. Luis Adram Drat, tomista.

2. El doctor D. Vicente Peris y Pascual, antitomista.

3. El Dr. D. Mariano Ximeno y Madramany, antitomista.

4. El Dr. D. Manuel Miralles, tomista.

5. El Dr. D. Francisco Pascual Tudela, antitomista.

6. El doctor D. Diodoro Esteve, tomista.

7. El Dr. D. Carlos Beneito, tomista.

8. El Dr. D. Jaime Pastor, antitomista.

9. EI Dr. D. Juan Bautista Carbonell, tomista.

10. El Dr. D. Pascual Vicente Llanzol, antitomista. 
11. El Dr. D. Francisco Martínez y Esteban, antitomista.

12. El Dr. D. Carlos Primo y Costa, antitomista.

13. El doctor D. Mariano Simó y Gil, antitomista.

14. EI Dr. D. Gaspar Pérez Gómez, antitomista.

15. El doctor D. Juan Gascó, tomista.

16. El Dr. D. Joaquín Más, tomista.

En suposición de haber sido estos dieciséis los opositores a la cátedra de teología expositiva con anexa pavordía vacante, y de haber tenido y ejercitado los dichos opositores los actos literarios prescritos y acostumbrados, el ilustre cabildo y regimiento de la muy noble y magnífica y fiel ciudad de Valencia, teniendo presente las órdenes de V.A. y arreglándose a ellas, en el día primero del mes de marzo de este presente año de 1774 , habiendo concurrido en la sala capitular veinte y dos que debían votar, en efecto votaron todos y reconociendo el número de votos del Ayuntamiento don Tomás Tinagero, su secretario, resultó que el doctor D. Vicente Peris, que es el segundo en antigüedad, en la primera votada tuvo catorce votos; el doctor D. Manuel Miralles seis votos; el Dr. D. Carlos Beneito dos votos; que todos eran los mismos veinte y dos vocales, según lo atestigua el secretario del Ayuntamiento; lo cual igualmente vio el regidor decano don Manuel Marmanillo; y habiéndose pasado a la mesa de la secretaría, los publicó el secretario.

Después se procedió a la segunda votada, para el segundo lugar de la terna; y habiéndose practicado las solemnidades rituales con arreglo a las órdenes de V.A., resultó que el Dr. D. Luis Adram Drat tenía cuatro votos; el doctor don Vicente Peris dos; el doctor don Manuel Miralles uno; el Dr. Carlos Beneito cuatro; el doctor don Jaime Pastor siete; el Dr. D. Pascual Tudela dos; el Dr. D. Diodoro Esteve uno; el Dr. D. Juan Bautista Carbonell uno. Lo que asimismo vio el regidor decano, y pasado a la mesa de la secretaría, se contaron y publicaron todos los veinte y dos votos.

Habiendo procedido últimamente a la votada para el tercer lugar de la terna, y habiéndose practicado todo formalmente, como en la primera y segunda, resultó tener el doctor Pascual Tudela siete votos; el doctor Diodoro Esteve tres votos; el doctor Carlos Beneito tres votos; el doctor Jaime Pastor dos votos; el doctor Juan Bautista Carbonell cuatro votos; y el doctor Pascual Llansola tres votos; los que vistos por el regidor que hacía de decano, se pasaron a la mesa de la secretaría, y el secretario del Ayuntamiento los leyó y publicó. Y éstas fueron las tres votadas según lo ha certificado dicho secretario.

Ahora ocurre la dificultad sobre si la primera votada que se hizo merece que V.A. la apruebe o repruebe. Aquí es necesaria la imparcialidad, y no tenemos que hacer sino observar, si antes de ella, y en ella, se han guardado y cumplido, o no, todo lo que V.A. tiene prescrito y mandado.

En veinte de diciembre de mil setecientos y sesenta y ocho mandó V.A. que en adelante se expresen las consultas el número de votos que hubiere a favor de cualesquiera opositores en el lugar competente. Así se ha ejecutado.

En veinte y siete de enero de mil setecientos setenta y dos mandó V.A.: "Que se saquen a concurso las pavordías primarias y demás (cátedras) que se hallaren vacantes, y que la Juntá de Patronato admita a oposición indistintamente a todos los profesores que se presentaren, forme ternas para cada una de por sí, y sin perjuicio de su Patronato las remila por esta vez al Consejo, con una lista de todos los opositores que hubiere habido a cada cátedra, con las relaciones de sus méritos y ejercicios'. V.A. ha sido obedecido en todo esto, y en lo demás que 
ha mandado, y lo vemos cumplido en lo tocante a la cátedra de teología expositiva con anexa pavordía, para cuyo obstento han concurrido diez y seis opositores, todos habilitados conforme V.A. lo tiene ordenado y mandado.

La enseñanza pública pide que, en los concursos literarios, se prefiera el más benemérito.

Es más benemérito el que, siendo hombre de bien y honesto en las costumbres, prudentemente se juzga que sabe mejor lo que ha de enseñar, y tiene mayor aplicación al cumplimieto de su obligación.

Se ha de enseñar la doctrina que san Pablo llamó sana; y sabrá enseñarla mejor el que en el asunto de que se trata ha hecho mayor estudio, acompañado de la erudición conveniente para su inteligencia, y de la claridad que pide la explicación de las cuestiones oscuras.

No dcbe uno (cualquiera que sea) ser excluido de una elección hecha legal y canónicamente, por haber tenido el nombre de antitomista, sino por ser sectario de la doctrina característica de los regulares expulsos, esto es, por defender que es lícito el regicidio, o por otras opiniones depravadas que han maleado y pervertido las costumbres cristianas, o que son contrarias a los legítimos derechos de los soberanos.

De otra suerte, V.A. mismo, en algún buen sentido, no rehusara el nombre de antitomista, pues juzga y obra contra las falsas decretales, defendiendo con valor la jurisdicción real y la verdadera de la primitiva y verdadera disciplina eclesiástica.

V.A. es antitomista, pues juzga según la verdad que tiene por evidente y no según la que ve que falsamente se ha alegado, y que sólo se ha probado aparentemente, no pudiéndose llamar probado respecto del juez lo que no se hace que crea él.

V.A. es antitomista, pues no cree que el alma de Trajano, después de haber sido condenada, se salvó.

V.A. es antitomista, pues defiende el misterio de la Purísima Concepción de la Virgen Madre de Dios. Y a este tenor podría yo añadir mucho más, que el estado presente de las cosas pide que se calle.

Esto supuesto, de los catorce capitulares que votaron por el doctor don Vicente Peris, no sabemos individualmente quién fue cada uno de ellos, ni de qué opinión. Cualesquiera que en particular los veinte y dos votos, habiendo tenido catorce el doctor Peris, ciertamente ha tenido parte de unos, y parte de otros, considerados todos en cuanto a las opiniones que siguieron, o no siguieron.

El que legítimamente es admitido al concurso tiene derecho para ser elegido, y supuesto el mérito acompañado de la habilidad para ejercitar el empleo debidamente, su elección merece ser aprobada, si no es que tenga algún impedimento legal o canónico.

El doctor Peris, que ha tenido en su favor mayoría de votos con mucho exceso a todos los demás opositores, es sacerdote de buenas costumbres, ejercitado en enseñar en sus sermones morales, con aprobación pública y general, la doctrina verdaderamente cristiana; hombre de genio pacífico, retirado, inteligente en la Sagrada Escritura, que es lo que pide la cátedra de teología expositiva con anexa pavordía. Ha defendido sus conclusiones muy llenas de doctrina, muy sobre sí, con sosiego de ánimo y con inteligencia de lo que se le ha propuesto, satisfaciendo bien a sus arguyentes. Ha esforzado sus argumentos con eficacia y modestia. Ha leído de puntos con solidez de doctrina, buen método y claridad. Con la última oposición que hizo a una pavordía, estando todavía en España los regulares de la compañía, fue combatido de ellos con extraordinario conato. $Y$ así injustamente se le objeta haber sido antitomista, interpretando esta voz en mal sentido. Finalmente, yo no sé que el doctor Peris tenga vicio legal o canónico, ni aun político, por el cual deba ser excluido del derecho de la cátedra de expositiva con anexa 
pavordía, que es prebenda eclesiástica de colación; habiendo tenido de su parte la mayoría de votos con tanto exceso a los demás opositores; $y$, si comparamos sus méritos con los que han presentado los autores del Memorial y usamos del peso del santuario, y no del de Canáán, me persuado que los del doctor Peris, atendidas las circunstancias de su bondad, virtud, ciencia y prudencia, son de mayor peso.

La pretensión, pues, de los autores del Memorial, en todas las proposiciones que contiene, tan fundada como se ve, parece meramente interesal y hecha con desconfianza de los propios méritos. En ella se trata de mantener los dos partidos opuestos, y consiguientemente las discusiones y discordias. Se supone, y no se prueba, la pertinacia de sus émulos, la cual bastaría para su exclusión absoluta; y se pide injustamente la alternativa. ¿Pero qué alternativa? Una de muchas cátedras, todas ahora de presente, para los suplicantes; y la otra alternativa para cuando sus contrarios sean hábiles; siendo ahora ellos mismos los acusadores y jueces de su inhabilidad. Omito otras consideraciones semejantes por no ser molesto a V.A.

Mi parecer, pues, en este espinoso asunto, es el mismo que el de fray Alonso de Castro; y mi expectación esperar, ver y venerar la resolución de V.A., que será conforme la justicia, el bien público y el sosiego de estos ánimos alborotados, que parece que dan indicios de pedir que se practique aquella máxima de los políticos del mundo, reprobada del Apóstol en su Epístola a los Romanos, como justamente condenada por Dios: "Faciamus mala ut veniant bona, quorum damnatio justa est". El medio que para esto han propuesto es oprimir a un hombre justo, con el espacioso pretexto del bien del partido de los que se llaman tomistas, siendo así que la única sentencia que se debe seguir es la que nos enseñó el mismo san Pablo: "Omnia et in omnibus Christus".

A todo lo dicho, pues, únicamente tengo que añadir que frecuentemente tendrá la molestia de recibir muchos impertinentes recursos, si no manda severamente que no haya otra escuela que la de Jesucristo al cual es consiguiente que solamente se tenga por ilícita la doctrina anticatólica.

Que la doctrina de las escuelas no se coarte a la que enseñaron san Agustín y santo Tomás, porque si no, la agustiniana y tomista serán más fuertemente contrarias que la tomista y antitomista.

Que el nombre de tomista no sirva para insultar a otros, explorando si siguen o no a santo Tomás.

Que en los asuntos pertenecientes a los dogmas de la religión cristiana por ahora no se citen en las disputas literarias, para su comprobación, sino las Divinas Escrituras, las Tradiciones apostólicas y los sagrados cánones de los Concilios ecuménicos.

Que los testimonios de los santos sirvan para probar el lugar teológico de su autoridad.

Que en la filosofía se siga el Compendio Filosófico del Dr. Tomás Vicente Tosca, con lo cual se quitará la ocasión de introducir el materialismo y la impiedad; pero no se ha de seguir de manera que en algunas cuestiones no se pueda dejar de seguir.

Que las Divinas Escrituras se expliquen todas en sentido literal, versículo por versículo, habiendo dos cátedras, una del Antiguo Testamento y otra del Nuevo, cosa más fácil de ejecutar que lo que piensan muchos, y que es muy conforme a los estudios de los Santos Padres de la Iglesia primitiva.

Que haya un curso teológico que solamente sea dogmático, y otro de teología moral.

Y finalmente, para desahogo de los genios escolásticos, que haya una cátedra de mera escolástica, refiriendo sencillamente lo que con alguna verosimilitud discurrieron los príncipes de las sectas escolásticas y sus más aventajados discípulos, respectivamente a los dogmas y para su 
explicación, juntando las opiniones y no altercando sobre ellas, de suerte que sea una secta historial, instructiva y nada rencillosa.

Si V.A. no manda que se apliquen éstos y semejantes remedios, las Universidades serán unas hidras de setecientas mil cabezas. Quiera Dios que no suceda así, y que las sabias providencias de V.A. refrenen los genios alborotadores de la quietud pública. Valencia a 21 de junio de 1774 .

Don Gregorio Mayáns y Sisca

BAHM, 191 